\title{
ON PRICE CO-MOVEMENT AND VOLATILITY SPILLOVER EFFECTS IN CHINA'S HOUSING MARKETS
}

\author{
Yingliang WENG a, Pu GONG a,* \\ a School of Management, Huazhong University of Science and Technology, Wuhan 430074, China
}

Received 11 January 2016; accepted 4 November 2016

\begin{abstract}
The soaring property prices in many Chinese cities have recently attracted increasing attention. This study uses the data on housing price indices from January 2005 to December 2014 in 10 large Chinese cities to analyze volatility spillover effects and to identify the determinants of price co-movement across the China's regional housing markets. This research proposes a novel dynamic spatial panel data model that accounts for multivariate asymmetrical generalized autoregressive conditional heteroskedasticity components in disturbances to address these issues empirically. Results reveal that housing prices in cities are significantly influenced by population, income, mortgage rates, policy factors, and the national macroeconomic situation. The analysis further indicates that the housing returns of regions in China that are in close geographic and economic proximities exhibit strong co-movement and volatility spillovers. Evidence of significantly positive leverage effects in regional housing markets is also determined. This study's findings have significant implications for academic researchers, financial experts, and policy makers.
\end{abstract}

KEYWORDS: Housing markets; Price co-movement; Volatility spillover effects; Spatial econometrics; Leverage effects

SUPPLEMENTARY MATERIAL associated with this article can be found, in the online version, at https://doi.org/10.3846/1648715X.2016.1271369

\section{INTRODUCTION}

Housing is often considered a heterogeneous good in finance and economics, and includes physical characteristics (e.g., construction conditions, internal area, and age) and neighborhood characteristics (e.g., accessibility to central business district, distance to subway stations, and behavior of nearby residents). Although a considerable number of recent studies regarding the heterogeneity of property submarkets have been made, the interaction among different regional housing markets with different characteristics is another critical point required to better understand the real estate market (Alkan 2015; Chiang 2016). Thus, one issue that should be addressed is whether different regional housing markets are related to one another because of the information linkages/spillovers across regional housing markets. The specific questions that should be answered are as follows: What is the essential feature of the correlations among regional housing markets? How can the dy-

* Corresponding author. E-mail: gongpu@hust.edu.cn namic co-movements of housing returns among different regions be modeled? Do any leverage effects, that is, asymmetric responses to positive and negative shocks, exist in China's housing markets? Because housing price variability is often considered a reflection of consumer confidence and the performance of the entire financial market, the answers to the aforementioned questions have theoretical and actual operational implications for academic researchers, financial experts, and policy makers (Brunauer et al. 2013; Kallberg et al. 2014).

The present study aims to empirically analyze volatility spillover effects and to identify the determinants of the co-movements of housing prices across 10 regional housing markets in China from January 2005 to December 2014. In general, the comovement and volatility spillovers in housing returns are often attributed to the change in demand for properties because of information linkages across regional housing markets and information spillovers resulting from interregional trades. Many factors such as migration, purchasing investment 
properties, and contagious reactions to information linkages across housing markets can result in spatial interactions and volatility spillovers among regional housing markets. For instance, Shiller (1994) found that investors often focus on observing what is happening in other similar regions instead of analyzing the overall macroeconomic development situation when predicting their own market performance. Moreover, the outbreak of the global financial crisis in 2007-2009 once again showed that global financial markets are more interconnected among cities, states, regions, and countries (Bauwens et al. 2006; Gong, Weng 2016; Weng, Gong 2016).

Several studies have provided a few beneficial methodologies in investigating volatility spillover effects; these methodologies are mainly based on multivariate time-series models, such as the multivariate generalized autoregressive conditional heteroskedasticity (MGARCH) (Bollerslev 1986; Engle 2002; Engle et al. 2012). However, two main difficulties arise in the process of estimating the MGARCH models: one is that such models contain a large number of unknown parameters, and the other is that such models are based on the assumption that the conditional covariance matrix is positive definite. For example, Engle and Kroner (1995) showed that the number of unknown parameters is proportional to the fourth power of the number of dependent variables in general MGARCH models. By contrast, dynamic spatial panel (DSP) data models, which contain fewer parameters than MGARCH models and can capture the spatial dependencies among crosssectional units intuitively, are highly popular among researchers (Anselin 1988; Elhorst 2014; Gong, Weng 2016; Parent, LeSage 2011; Seya et al. 2013). Therefore, this study incorporates certain spatial components into the MGARCH models and then empirically investigates one-to-one spatial dependence between China's regional housing markets using the proposed models.

Particularly, we adopt a DSP data model with multivariate asymmetrical GARCH terms in disturbances, which is a combination of the DSP data model and the multivariate Glosten-JagannathanRunkle (GJR)-GARCH model (DSP-GJR-GARCH, hereafter) suggested by Glosten et al. (1993). The DSP-GJR-GARCH model is used to investigate the spatial interactions in the housing returns and time-variant conditional volatilities across China's regional housing markets. The advantages of the DSP data models are that they can capture the spatial dependencies and the serial correlations simultaneously. In recent years, the specifications and estimations of such models have been studied by numerous researchers (Baltagi et al. 2014; Elhorst 2014). Spatial models are known to be characterized by spatial weight matrix (SWM), which incorporates the spatial structures into the models in advance. Thus, constructing a SWM appropriately plays a key role in estimating the spatial dependence parameters of DSP data models. Indeed, experts and scholars have focused on investigating this subject for many years. For example, to effectively demonstrate the effects of both the geographic and economic indicators on the housing markets, Case et al. (1993) used a compound SWM that is a combination of the geographic distance SWM and the economic distance SWM. Recently, Kelejian and Piras (2014) proposed a new endogenous SWM specification method. As discussed, this paper follows the works of Case et al. (1993) and Zhu et al. (2013), and employs the Mahalanobis distance to construct an economic distance SWM using relevant economic indicators, such as regional gross domestic product (GDP), employment rate, housing satisfaction, and housing expectations $^{1}$. We believe that regions with similar economic development conditions will exhibit strong co-movement because the Mahalanobis distance considers the correlations of economic indicators.

The results have important implications for portfolio managers, financial institutions, and policymakers in China. First, if the correlations of the regional housing markets are driven not only by geographic proximities but also by economic similarities, then formulating asset al.ocation strategies by considering only the geographic adjacency factors regardless of the economic similarity factors will lead to biases in investment decision making. Second, because regional housing markets are an integral part of the capital markets, the price comovement among these regional housing markets should be understood adequately in the pricing of securities in capital markets. For instance, ignoring correlations in the idiosyncratic risk and volatility spillovers between different regional housing markets may result in underestimating the actual risk of security prices. Generally, underpriced se-

\footnotetext{
${ }^{1}$ Mahalanobis distance is defined as a dissimilarity measure between two random column vectors $x$ and $y$ of the same distribution with the covariance matrix $V$ : $d(x, y)=\sqrt{(x-y)^{T} V^{-1}(x-y)}$, where the superscript $T$ denotes the matrix transpose and the matrix $V^{-1}$ represents the inverse of the matrix $V$. This dissimilarity measure is extensively used in cluster analysis and other classification techniques.
} 
curities are likely to result in an overactive market. Finally, the results show that China's housing market is characterized by apparent volatility spillover effects among 10 large cities, and only the macro-control policy issued by the State Council in May 2006 has a significant and positive effect on regional housing returns and fluctuations. This situation explains why China's macro-control policies to promote the steady and sound development of the housing market since 2005 have had a minimal impact on housing prices throughout the country. Since the price co-movement among regional housing markets is clear, the authorities must realize this point and take relevant and effective measures to fight housing price appreciation.

This paper is organized as follows. Section 2 briefly reviews the relevant literature on spatial econometric models and volatility spillover effects. In Section 3, we introduce our DSP-GJR-GARCH model, discuss the stationary conditions of parameters, and describe the maximum likelihood (ML) estimation procedures. The empirical results are reported and discussed in Section 4, and the conclusion is presented in Section 5.

\section{LITERATURE REVIEW}

Volatility is one of the most important research objects in finance and economics. Estimating, modeling, and forecasting volatilities of security prices play a key role in areas such as portfolio selection, risk management, and asset pricing. In recent years, related studies on how to model volatility spillovers across asset types (e.g., among stock, bond, and currency markets) or across regional markets (e.g., among stock markets that are located in different regions) have become increasingly thorough and popular. The seminal work by Engle (1982) and the initial GARCH model proposed by Bollerslev (1986) seem to be the frequently used frameworks in modeling and forecasting volatilities of financial time series. Nevertheless, because of the cross-sectional dependencies or cross-sectional heterogeneities across assets/markets, some extended MGARCH models have been investigated in the past decades. Representative works in this area include the vector error correction (VEC)-GARCH model of Bollerslev et al. (1988), the Baba-Engle-Kraft-Kroner (BEKK)-GARCH model of Engle and Kroner (1995), the constant conditional correlation (CCC)-GARCH model of Bollerslev (1990), and the dynamic conditional correlation (DCC)-GARCH model of Engle (2002).
Housing markets are an integral part of the capital markets; thus, studies on how to measure the housing price variability and on how to investigate the volatility spillovers across regional housing markets are essential in risk management. In summary, the relevant literature on volatility spillover effects across housing markets can be classified into two main categories.

One group of papers has explored the relationship between housing price variability and national macroeconomic development indicators like GDP, population, unemployment rate, and income (Apergis et al. 2015). Prominent examples of this category include the study by Dolde and Tirtiroglu (2002), who examined the relationship between housing price variability and the national macroeconomic conditions in the United States (US) from 1975 to 1993. They found significant correlations between housing price variability and the national macroeconomic development indicators such as national and regional income growth, inflation, and interest rates. In a recent work, Kallberg et al. (2014) investigated the co-movements of housing prices among 14 metropolitan areas in the US using the Standard \&Poor's/Case-Shiller (S\&P/CS) seasonally adjusted home price indices from 1992 to 2008. The results show that the fundamental factors such as population, disposable personal income, and GDP are statistically significant determinants of housing prices and the strengths of price co-movement among regional housing markets in the US increase after 2000. In addition, Zhang et al. (2014) analyzed the home price variability from the perspective of national and local forces using the S\&P/CS seasonally adjusted home price indices across 20 cities in the US from 1991 to 2012. They found that both national and local factors play a key role in determining the variability of local housing prices based on simultaneous equations. However, the explanatory power of national factors on local housing price changes is slightly stronger than those of local factors. Apergis et al. (2015) employed a panel co-integration approach to investigate the long- and short-term dynamics of the US metropolitan area housing prices in relation to personal income. They determined a long-term relationship between local housing prices and per capita personal income. In addition, Chiang (2016) used similar econometric approach to investigate interaction among the residential, office and retail markets in China but found no evidence of long-run equilibrium among them. 
Another set of studies has focused on the issue of spatial contagion of shocks across asset/markets. These studies concentrate on the spatial contagion of the economic shocks to neighboring markets or other markets with similarities. For instance, using MGARCH models, Michayluk et al. (2006) found significant leverage effects between US and United Kingdom (UK, hereafter) real estate markets. Hui and Chan (2013) investigated the contagion across the stock and real estate markets of four countries, namely, Greece, UK, US, and Hong Kong, during the European sovereign debt crisis. They obtained evidence of contagion across the stock and real estate markets. However, the contagion patterns in these markets differed from one another. Brady (2014) estimated the spatial diffusion of housing prices across the US states from 1975 to 2011 using a single-equation spatial model and showed that the more pronounced persistence of spatial diffusion occurred after 1999.

This paper aims to empirically investigate what drive the co-movements in housing prices and whether leverage effects and volatility spillover effects exist among China's regional housing markets. In fact, a series of studies have been conducted to answer similar questions on the US housing markets using the S\&P/CS seasonally adjusted home price indices. For instance, Miao et al. (2011) found significant spatial dependencies in housing returns and conditional variances across 16 metropolitan areas from 1989 to 2006 using the S\&P/ CS seasonally adjusted home price indices and a VAR-GARCH model. However, stronger spatial dependencies exist in the metropolitan areas located in the southern, western and eastern US. Similarly, Zhu et al. (2013), whose work is closely related to the present study, adopted a DSP model with GARCH (DSP-GARCH) components in the disturbances to explore the potential differences in regional real estate prices in the US from 1995 to 2009. They showed that interconnections across markets are affected by both geographic proximities and economic similarities. In addition, population, unemployment, lagged personal income growth, and mortgage rates are significantly correlated with housing prices in regional housing markets.

What these studies have in common are the data sources. The studies mainly adopt the S\&P/ CS seasonally adjusted home price indices and examine the regional housing markets in the US being subject to data availability. However, few studies have focused on investigating whether volatility spillover effects exist and what drive the co-movement in housing prices across China's regional housing markets. One main recent contribution is the study by Shih et al. (2014), who addressed the questions of whether housing price bubbles occur and whether the bubbles are spatially contagious among China's 28 provinces. Using quarterly housing price data from 2000 to 2012, they found that most of the provinces have bubbles and significant spillover effects exist among geographically adjacent regions. Another recent work by Chiang (2014) detected ripple effects among China's six first-tier cities from 2003 to 2013 by using the Toda-Yamamoto (TY) causality test. The results show that the ripple effect is characterized by a lead-lag relationship and Beijing is the main source of housing price appreciation, which should be targeted as the regulatory object. Thus, motivated by previous research, the present study investigates the forms of price co-movement and determines whether leverage effects and volatility spillover effects exist among regional housing markets in China.

\section{MODEL SPECIFICATIONS}

We adopt a DSP-GJR-GARCH model to ascertain whether volatility spillover effects exist and what drive the co-movements in local housing prices across China's regional housing markets. MATLAB software is used to conduct our model estimations.

\subsection{DSP-GJR-GARCH model}

Studies on volatility spillover effects in previous literature are mainly based on multivariate timeseries models such as MGARCH models. In contrast to the MGARCH models, the model used in this paper is a DSP data model with a multivariate GJR-GARCH disturbance and contains fewer unknown parameters because this model incorporates spatial correlation structures into models beforehand by using a SWM. Thus, the current model may be highly suitable for capturing the spatial dependencies and serial correlations among numerous cross-sectional units.

The model consists of three parts. The first part is a DSP data model, which is used to measure the spatial dependencies and serial correlations among regional housing returns. Following the definitions by Zhu et al. (2013), we define the interdependence as the lagged spatial dependence and the co-movement as a contemporaneous spatial dependence across housing markets. The second part is a spa- 
tial autoregressive model, which is used to measure the co-movements among unexpected shocks. The third part is a simple multivariate GJR-GARCH $(1,1)$ model, which is used to measure the timevarying conditional variances of housing returns. Furthermore, this part examines whether leverage effects and volatility spillover effects exist among China's regional housing markets. Following these ideas, the proposed DSP-GJR-GARCH $(1,1)$ model is formulated as:

$$
\begin{aligned}
& Y_{n t}=\varphi Y_{n, t-1}+\rho W Y_{n t}+\lambda W Y_{n, t-1}+X_{n t} \beta+u_{n}+ \\
& v_{t}+e_{n t}, \\
& e_{n t}=\delta W e_{n t}+\varepsilon_{n t}, \\
& \sigma_{n t}^{2}=\omega_{0}+\omega_{1} \varepsilon_{n, t-1}^{2}+\gamma \varepsilon_{n, t-1}^{2} \bar{I}_{n, t-1}+\psi W e_{n, t-1}^{2}+ \\
& \xi D+\omega_{2} \sigma_{n, t-1}^{2},
\end{aligned}
$$

where: $Y_{n t}=\left(y_{1 t}, y_{2 t}, \cdots, y_{n t}\right)^{\prime}$ is an $n \times 1$ vector that represents housing returns in period $t=1,2, \cdots, T$; $y_{i t}=\ln \left(p_{i, t} / p_{i, t-1}\right)$ denotes the housing return of region $i(i=1,2, \cdots, n$. $)$ in period $t ; p_{i t}$ is the housing price of region $i$ in period $t . X_{n t}$ denotes an $n \times k$ matrix of explanatory variables and $\beta$ is a $k \times 1$ coefficient vector. $u_{n}$ is the individual-specific fixed effect, $v_{t}$ is the time-specific fixed effect, and $e_{n t}$ is an $n \times 1$ vector of disturbances. $\varepsilon_{n t}$ is an $n \times 1$ error term and the elements of $\varepsilon_{n t}$ are independent identically distributed. We suppose that the conditional variance of $\varepsilon_{n t}$ is $\sigma_{n t}^{2}$ under the given information set $H_{n, t-1}$ in time $t-1$, i.e., $\varepsilon_{n t} \mid H_{n, t-1} \sim N\left(0, \sigma_{n t}^{2}\right)$. $\bar{I}_{n, t-1}=\left(I_{1, t-1}, I_{2, t-1}, \cdots, I_{n, t-1}\right)^{\prime}$ denotes an $n \times 1$ vector, where $I_{i, t-1}$ is the usual exception indicator

$$
I_{i, t-1}= \begin{cases}1 & \text { if } \varepsilon_{i, t-1}<0, \\ 0 & \text { if } \varepsilon_{i, t-1} \geq 0\end{cases}
$$

Note that $\varepsilon_{i, t-1}<0$ represents bad news while $\varepsilon_{i, t-1}>0$ represents good news. Therefore, the impacts of these two factors on conditional variance $\sigma_{n t}^{2}$ are different. Particularly, the impact of good news on conditional variance $\sigma_{n t}^{2}$ is $\omega_{1}$ while that of bad news on conditional variance $\sigma_{n t}^{2}$ is $\omega_{1}+\gamma$. Thus, the significantly positive sign of $\gamma$ suggests the existence of leverage effects among the regional housing markets.

In addition, we are interested in whether the key macro-control policies on the housing market issued by the State Council over the years have significant effects on the regional housing returns and fluctuations. In fact, China's central government, specifically the State Council, has adopted various macro-control measures to stabilize the development of housing market and to improve people's livelihoods in recent years (see Supple- mentary Appendix 1). For this analysis, we add a dummy variable $D$ in Eqs. (1) and (3), which represents the considered policy period ${ }^{2}$. The coefficient of the dummy variable $D$ in Eq. (1) reflects the effects of the key macro-control policy on the housing returns while the coefficient $\xi$ shows the difference of volatilities between policy and nonpolicy periods.

\subsection{Stationary conditions and ML estimations}

In this subsection, we first discuss the stationary conditions of parameters in our proposed models and then derive the corresponding ML estimators.

Let $R=I_{n}-\rho W, S=\varphi I_{n}+\lambda W$, then Eq. (1) can be transformed into the following form:

$$
R Y_{n t}=S Y_{n, t-1}+X_{n t} \beta+u_{n}+v_{t}+e_{n t} .
$$

For Eq. (5), stationary conditions are satisfied only if $\left|R S^{-1}\right|<1$, which requires:

$$
\begin{array}{ll}
\varphi+(\rho+\lambda) \eta_{\max }<1, & \text { if } \rho+\lambda \geq 0 \\
\varphi+(\rho+\lambda) \eta_{\min }<1, & \text { if } \rho+\lambda<0 \\
\varphi-(\rho-\lambda) \eta_{\max }>-1, & \text { if } \rho-\lambda \geq 0 \\
\varphi-(\rho-\lambda) \eta_{\min }>-1, & \text { if } \rho-\lambda<0
\end{array},
$$

where: $\eta_{\max }$ and $\eta_{\min }$ represent the max eigenvalue and the min eigenvalue of $W$, respectively.

For Eq. (2), stationary condition is satisfied only if $|\delta|<1$.

For Eq. (3), the stationary conditions of unknown parameters in the multivariate GJRGARCH $(1,1)$ model are as follows:

$$
\begin{aligned}
& \omega_{0}>0, \omega_{1}>0, \omega_{2}>0, \psi>0, \\
& \omega_{1}+\gamma>0, \\
& \omega_{1}+\frac{1}{2} \gamma+\omega_{2}>0 .
\end{aligned}
$$

Once the stationary conditions are satisfied, we can estimate the proposed model using the unconditional ML estimation method proposed by Elhorst (2005). We denote $R=I_{n}-\rho W$ and $B=I_{n}-\delta W$, then the models in Eqs. (1), (2), and (3) can be transformed into the following forms

$$
\begin{aligned}
& Y_{n t}=\varphi R^{-1} Y_{n, t-1}+\lambda R^{-1} W Y_{n, t-1}+R^{-1} X_{n t} \beta+ \\
& R^{-1} B^{-1} \varepsilon_{n t}, \\
& \sigma_{n t}^{2}=\omega_{0}+\omega_{1} \varepsilon_{n, t-1}^{2}+\gamma \varepsilon_{n, t-1}^{2} \bar{I}_{n, t-1}+\psi W e_{n, t-1}^{2}+ \\
& \xi D+\omega_{2} \sigma_{n, t-1}^{2} .
\end{aligned}
$$

\footnotetext{
2 The dummy variable $D$ takes the value of 1 if the national macro-control policy on the housing markets is issued, and takes the value of 0 otherwise.
} 
Then, the log-likelihood function of $Y=\left(Y_{n 1}^{\prime}, Y_{n 2}^{\prime}, \cdots, Y_{n T}^{\prime}\right)^{\prime}$ is

$\log L=-\frac{n T}{2} \ln (2 \pi)-\frac{1}{2} \sum_{t=1}^{T} \sum_{i=1}^{n} \ln \left(\sigma_{i t}^{2}\right)+T \ln |R|+$

$T \ln |B|-\frac{1}{2} \sum_{t=1}^{T} \sum_{i=1}^{n} \frac{\varepsilon_{i t}^{2}}{\sigma_{i t}^{2}}$,

where: $\beta, \varphi, \rho, \lambda, \delta, \omega_{0}, \omega_{1}, \omega_{2}, \gamma, \xi$ and $\psi$ are unknown parameters.

We obtain the estimates of the unknown parameters by maximizing Eq. (10). However, the accuracy of the estimates for unknown parameters generally depends on the preferences for the initial values of the parameters when using the ML estimation method. We believe that selecting the precise initial values is important to our study because our sample only includes 118 months, which is fairly small. A flexible initial condition can considerably reach convergence in the iteration for the ML function because our model is also relatively complex. Therefore, we prefer the unconditional ML estimator and provide the initial values of $\varepsilon_{n 1}$ and $\sigma_{n 1}^{2}$ by following the suggestions of Elhorst (2005), Hsiao et al. (2002), and Zhu et al. (2013) ${ }^{3}$.

\subsection{Specifications of spatial weight matrices}

In spatial econometrics, the SWM is a core element to reflect the possible relations between spatial locations. In general, a SWM can be defined as a spatial correlation function of geographic distance, economic distance, or social distance between cross-sectional units (Case et al. 1993; Ma, Liu 2013). Since one aim of this study is to choose the most appropriate SWM that can correctly capture the spatial interaction patterns among China's regional housing markets, a SWM that can reflect both the geographic relations and economic linkages between spatial units will be a reasonable choice. Thus, we follow the work of Case et al. (1993) and use the following compound SWM, which is a combination of the geographic SWM and the economic SWM.

$$
W=a W_{G}+(1-a) W_{E}, \quad 0 \leq a \leq 1,
$$

where: $W_{G}$ represents the geographic SWM and $W_{E}$ denotes the economic SWM.

${ }^{3}$ Infact, we suppose that $\varepsilon_{n 1}=B\left(R Y_{n 1}-\varphi \bar{Y}-\lambda W \bar{Y}-X_{n 1} \beta\right)$, $\sigma_{n 1}^{2}=\omega_{0}+\omega_{1} \bar{\varepsilon}^{2}+\gamma \bar{\varepsilon}^{2} \bar{I}_{n 0}+\psi W \bar{e}^{2}+\xi D+\omega_{2} \bar{\sigma}^{2}$, where $\bar{\sigma}^{2}$ is the sample variance, $\bar{Y}=T^{-1} \sum_{t=1}^{T} Y_{n t}, \bar{\varepsilon}=T^{-1} \sum_{t=1}^{T} \varepsilon_{n t}$, and $\bar{e}=T^{-1} \sum_{t=1}^{T} e_{n t}$.
With respect to the geographic SWM, the longer the distance between the two regional housing markets, the higher is the interaction cost such as travel time. Thus, when constructing $W_{G}$, we regard all spatial locations as the neighbor of each other, but we believe that the interaction between nearer neighbors are larger than that between farther neighbors. In this case, we use the following popular bi-square kernel function form

$$
w_{i j}^{G}= \begin{cases}{\left[1-\left(d_{i j} / \bar{d}\right)^{2}\right]^{2}} & \text { if } d_{i j} \leq \bar{d}, \\ 0 & \text { if } d_{i j}>\bar{d},\end{cases}
$$

where: $w_{i j}^{G}$ represents the geographic weight between regions $i$ and $j ; d_{i j}$ is the straight line distance between regions $i$ and $j$, and parameter $\bar{d}$ refers to the kernel bandwidth. The function is continuous until a distance threshold $\bar{d}$ is reached and then becomes zero beyond the threshold. The kernel bandwidth is the key controlling parameter and can be specified either by a fixed or an adaptive bandwidth (Wheeler 2014). In our empirical illustration, we choose a fixed bandwidth of $\bar{d}=1591$ kilometer $(\mathrm{km})$, which is the median quartile distance between two regions ${ }^{4}$. To effectively reflect how spatial correlations vary with the geographical distance, we change parameter $\bar{d}$ from the first quartile distance to the maximum distance between any two regions ${ }^{5}$. The optimal threshold $\bar{d}$ is determined by the maximum log-likelihood value and the significance of the regression coefficients, and the details for choosing $\bar{d}$ appropriately are included in Supplementary Appendix 3.

Additionally, we support the view that stronger spatial dependencies exist among regions with more similar economic development conditions. Therefore, following the work of Zhu et al. (2013), we adopt the Mahalanobis distance to construct our economic SWM using the macro-economic relevant indicators. Particularly, the element in the economic SWM $W_{E}$ is defined as follows:

$$
w_{i j}^{E}= \begin{cases}e^{-\left[\left(E_{i}-E_{j}\right)^{\prime} V^{-1}\left(E_{i}-E_{j}\right)\right]^{0.5}} & i \neq j, \\ 0 & i=j,\end{cases}
$$

where: $E_{i}$ represents the economic indicator vector for region $i(i=1,2, \cdots, n$. $)$, and $V$ denotes the sample variance-covariance matrix.

\footnotetext{
${ }^{4}$ In fact, the similar geographic SWM specification method has been adopted by Wang et al. (2015), who studied the economic volatility co-movement across countries using spatial models and confirmed that the strongest spatial dependence, if any, should occur among countries that are closest to each other. However, differently from them, we adopt the bi-square kernel function instead of inverse distance kernel function based on comparison of the goodness-of-fit.

5 The first and third quartile cutoff distances are $1125 \mathrm{~km}$ and $2020 \mathrm{~km}$, respectively. The maximum distance in our sample is $2842 \mathrm{~km}$ between Hangzhou and Chengdu.
} 
The economically relevant indicators adopted in this paper consist of regional GDP, per capita income of urban households, registered urban employment rate, residential satisfaction of city dwellers, and indicators that can reflect the housing market conditions such as the housing price expectations and the standard deviations of the housing price expectations. However, differently from the definitions of Zhu et al. (2013), these variables are the average values covering the period from 2005 to $2014^{6}$.

To avoid the singularity of matrix, we first rownormalize $W_{G}$ and $W_{E}$ such that each row sums to 1 . Then, we substitute $W$ in Eq. (11) into Eqs (1), (2), and (3), and we obtain the following equation

$$
\begin{aligned}
& Y_{n t}=\varphi Y_{n, t-1}+\rho\left[a W_{G}+(1-a) W_{E}\right] Y_{n t}+ \\
& \lambda\left[b W_{G}+(1-b) W_{E}\right] Y_{n, t-1}+X_{n t} \beta+u_{n}+v_{t}+e_{n t}, \\
& e_{n t}=\delta\left[c W_{G}+(1-c) W_{E}\right] e_{n t}+\varepsilon_{n t}, \\
& \sigma_{n t}^{2}=\omega_{0}+\omega_{1} \varepsilon_{n, t-1}^{2}+\gamma \varepsilon_{n, t-1}^{2} \bar{I}_{n, t-1}+\psi_{G} W_{G} e_{n, t-1}^{2}+ \\
& \psi_{E} W_{E} e_{n, t-1}^{2}+\xi D+\omega_{2} \sigma_{n, t-1}^{2},
\end{aligned}
$$

where: $a, b$, and $c$ represent the proportions of the geographic SWM in the compound SWM for the contemporaneous spatial dependencies in the housing returns, one-period lagged spatial dependencies in the housing returns, and spatial dependencies in the error terms, respectively; $\psi_{G}$ and $\psi_{E}$ denote the coefficients of geographic volatility interdependence and economic volatility interdependence, respectively.

\section{EMPIRICAL RESULTS}

\subsection{Data sources and description}

Monthly regional housing price indices are obtained from China Real Estate Index System (CREIS), which is compiled by SouFun Holdings Limited, a company listed on the New York Stock Exchange. Specifically, the housing price index data are derived from an urban composite index of new dwellings, which includes residential, office, and retail properties ${ }^{7}$. The index is a kind of Laspeyres index with a base point of 1,000 in Beijing as of December 2000, calculated on the basis of market investigations on selling prices of typical new dwellings in different cities.

\footnotetext{
${ }^{6}$ In fact, the results using the SWM specifications proposed by Zhu et al. (2013) are almost the same as the results presented in Table 4 . The housing expectation is calculated as $E X P_{t}=\frac{1}{3} \sum_{s=1}^{3} H R_{t-s}$, where $E X P_{t}$ represents the housing expectation in period $t$, and $H R_{t-s}$ represents the housing returns in period $t-s$.

${ }^{7}$ According to CREIS, the urban composite index is calculated by a weighted average of 0.75 for residential, 0.15 for office, and 0.1 for retail properties, respectively.
}

Our motivation for collecting data from CREIS is twofold. First, recent studies have mainly investigated the mean and volatility spillover effects from mature housing markets and we intend to continue in this direction while focusing on China's housing market, which represents emerging housing markets. Second, the reliability of the housing price index significantly depends on the quality and suitability of the data and a national uniform data source from CREIS that can permit quality control of the data. Indeed, Hui and Yue (2006) adopted the residential price index data from CREIS to investigate whether a housing price bubble occurred in Beijing and Shanghai in 2003. Using the same data source, Chiang (2014) investigated whether ripple effects exist among six first-tier Chinese cities.

We choose 10 national central cities or regional central cities located in different regions to reflect the differences in regional housing price development and to better understand China's housing market. Figure 1 demonstrates the locations of the studied areas. Particularly, Beijing, Shanghai, Guangzhou, Tianjin and Chongqing are the 5 national central cities that have strong economic power and rapid economic development; Shenzhen, Nanjing, Wuhan, and Chengdu are the regional central cities that lead the development of the regional cities, while Hangzhou is an eastern coastal city. In terms of geographic locations, twin cities Beijing and Tianjin are located in the north; Shanghai, Nanjing, and Hangzhou are in the east; Wuhan, Guangzhou, and Shenzhen are in south central China; Chongqing and Chengdu are in west China. These large cities have millions of resident populations and great economic strength, as described in Supplementary Appendix 2. These cities are diversely distributed in China, and therefore can be used to represent the regional housing markets. Since the monthly housing price indices have been released by the China Index Academy (CIA) since January 2005, our sample period ranges from January 2005 to December 2014, which is equivalent to a total of 120 months. The housing returns are calculated as $R_{t}=100 \times \ln \left(P_{t} / P_{t-1}\right)$, where $P_{t}$ and $P_{t-1}$ are the real regional housing price index, which is a nominal regional housing price index from CREIS divided by the consumer price index (CPI) to isolate the effect of inflation in periods $t$ and $t-1$, respectively ${ }^{8}$.

Table 1 presents the descriptive statistics and stationary test results for the monthly returns for

\footnotetext{
8 The regional CPI data adopted are obtained from $\mathrm{Na}$ tional Bureau of Statistics and represent a monthly fixedbase index with December 2004=100 as base month.
} 


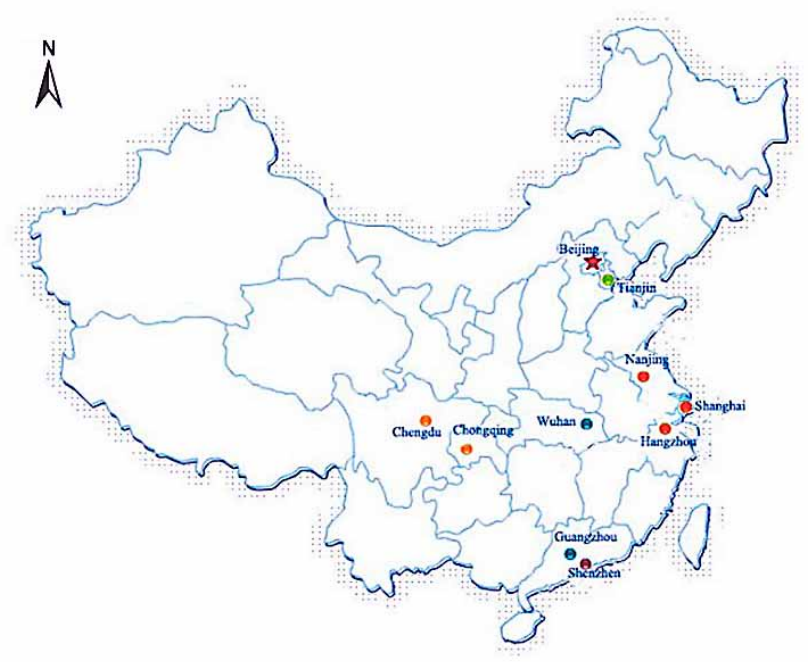

Fig. 1. Locations of the 10 cities

each of the 10 urban composite indices. As shown in Table 1, all the average housing returns are significantly positive, the kurtoses are larger than 3.98, and the Jarque-Bera (J-B) statistics are significantly different from zero. These results indi- cate that the distribution of the housing returns is characterized not by normal distribution but by fat tails. In addition, the Augmented Dickey-Fuller (ADF) statistics, which are significantly different from zero, show that the series of housing returns are stationary.

Table 2 presents the correlation matrix for the time series of monthly housing returns for $10 \mathrm{ur}$ ban composite indices. The results show that most correlation coefficients between each two regional housing markets are positive. In general, the correlation coefficients between two regional housing markets with closer geographical distances are larger than those between markets with farther geographical distances. However, the correlation coefficient between Beijing and Guangzhou is 0.636, which is relatively high although these two cities are geographically far (approximately $2267 \mathrm{~km}$ ) from each other. One reason for such a situation may be that the economic development situation in Beijing is similar to that in Guangzhou. For instance, they both are national central cities and

Table 1. Summary statistics and stationary test

\begin{tabular}{llllllllll}
\hline Region & Mean & Median & Max. & Min. & St. dev. & Skew & Kurt & $\begin{array}{l}\text { J-B } \\
\text { statistics }\end{array}$ & $\begin{array}{l}\text { ADF } \\
\text { statistics }\end{array}$ \\
\hline Beijing & 0.800 & 0.597 & 8.204 & -8.305 & 1.644 & -0.468 & 12.653 & $462.491^{* * *}$ & $-7.432^{* * *}$ \\
Tianjin & 0.481 & 0.460 & 7.398 & -4.254 & 1.566 & 0.768 & 6.283 & $64.603^{* * *}$ & $-9.457^{* * *}$ \\
Shanghai & 0.272 & 0.286 & 3.086 & -7.707 & 1.323 & -2.150 & 14.162 & $703.470^{* * *}$ & $-8.159^{* * *}$ \\
Nanjing & 0.346 & 0.569 & 6.233 & -8.954 & 1.933 & -1.274 & 8.566 & $184.278^{* * *}$ & $-9.510^{* * *}$ \\
Hangzhou & 0.217 & 0.266 & 3.832 & -8.894 & 1.576 & -1.987 & 13.173 & $586.418^{* * *}$ & $-4.840^{* * *}$ \\
Wuhan & 0.586 & 0.655 & 4.062 & -4.387 & 1.408 & -0.179 & 3.978 & $5.326^{* * *}$ & $-8.193^{* * *}$ \\
Guangzhou & 0.475 & 0.453 & 6.062 & -11.019 & 1.896 & -1.547 & 13.785 & $618.950^{* * *}$ & $-8.568^{* * *}$ \\
Shenzhen & 0.755 & 0.659 & 14.771 & -12.609 & 2.389 & 0.712 & 20.675 & $1545.970^{* * * *}$ & $-6.613^{* * * *}$ \\
Chongqing & 0.329 & 0.423 & 12.192 & -5.199 & 1.968 & 1.484 & 13.295 & $564.382^{* * *}$ & $-9.105^{* * *}$ \\
Chengdu & 0.256 & 0.324 & 6.673 & -9.605 & 1.800 & -0.914 & 10.757 & $312.223^{* * *}$ & $-8.756^{* * *}$ \\
\hline
\end{tabular}

Notes: The units of variables mean, median, max, min and standard deviation are in percentage. The sign ${ }^{* * *}$ denotes significance at the 0.01 level.

Table 2. Correlation results for squared housing returns (volatility)

\begin{tabular}{|c|c|c|c|c|c|c|c|c|c|c|}
\hline Region & Beijing & Tianjin & $\begin{array}{l}\text { Shang- } \\
\text { hai }\end{array}$ & Nanjing & $\begin{array}{l}\text { Hang- } \\
\text { zhou }\end{array}$ & Wuhan & $\begin{array}{l}\text { Guang- } \\
\text { zhou }\end{array}$ & $\begin{array}{l}\text { Shenz- } \\
\text { hen }\end{array}$ & $\begin{array}{l}\text { Chong- } \\
\text { qing }\end{array}$ & Chengdu \\
\hline Beijing & 1.000 & & & & & & & & & \\
\hline Tianjin & 0.102 & 1.000 & & & & & & & & \\
\hline Shanghai & $0.624^{* * *}$ & $0.158^{*}$ & 1.000 & & & & & & & \\
\hline Nanjing & $0.242^{* * *}$ & $0.833^{* * *}$ & $0.355^{* * *}$ & 1.000 & & & & & & \\
\hline Hangzhou & $0.318^{* * *}$ & 0.131 & $0.380^{* * *}$ & $0.232^{* * *}$ & 1.000 & & & & & \\
\hline Wuhan & -0.027 & $0.164^{*}$ & 0.060 & 0.041 & 0.003 & 1.000 & & & & \\
\hline Guangzhou & $0.636^{* * *}$ & $0.195^{* * *}$ & $0.870^{* * *}$ & $0.355^{* * * *}$ & $0.366^{* * *}$ & 0.111 & 1.000 & & & \\
\hline Shenzhen & $0.914^{* * *}$ & $0.266^{* * * *}$ & $0.537^{* * *}$ & $0.372^{* * * *}$ & $0.291^{* * *}$ & -0.036 & $0.552^{* * *}$ & 1.000 & & \\
\hline Chongqing & $0.693^{* * *}$ & 0.131 & 0.087 & 0.118 & 0.118 & 0.031 & 0.085 & $0.821^{* * * *}$ & 1.000 & \\
\hline Chengdu & $0.212^{* *}$ & $0.451^{* * * *}$ & 0.110 & $0.479^{* * *}$ & 0.076 & 0.120 & $0.217^{* *}$ & $0.284^{* * *}$ & $0.166^{*}$ & 1.000 \\
\hline
\end{tabular}

Notes: The signs ${ }^{* * *},{ }^{* *}$, and ${ }^{*}$ denote significance at the $0.01,0.05$, and 0.1 levels, respectively. 
Table 3. Description of variables

\begin{tabular}{|c|c|c|c|c|c|c|c|c|c|c|}
\hline \multirow[t]{2}{*}{ Region } & \multicolumn{2}{|c|}{ Population } & \multicolumn{2}{|c|}{$\begin{array}{l}\text { Per capita dispos- } \\
\text { able income }\end{array}$} & \multicolumn{2}{|c|}{$\begin{array}{l}\text { Unemployment } \\
\text { rate }\end{array}$} & \multicolumn{2}{|c|}{ Regional GDP } & \multicolumn{2}{|c|}{$\begin{array}{l}\text { Number of practi- } \\
\text { tioners }\end{array}$} \\
\hline & Mean & St. dev. & Mean & St. dev. & Mean & St. dev. & Mean & St. dev. & Mean & St. dev. \\
\hline Beijing & 1256.33 & 45.08 & 29375.90 & 7993.08 & 1.57 & 0.30 & 13757.87 & 4471.62 & 673.91 & 106.48 \\
\hline Tianjin & 1009.08 & 92.20 & 22913.60 & 6531.25 & 3.59 & 0.06 & 9138.03 & 3841.69 & 707.29 & 107.65 \\
\hline Shanghai & 1401.88 & 23.81 & 31826.60 & 8980.84 & 4.26 & 0.08 & 16335.27 & 4379.03 & 1061.15 & 104.56 \\
\hline Nanjing & 627.35 & 14.93 & 28076.30 & 8569.87 & 2.94 & 0.28 & 5178.42 & 2049.92 & 555.01 & 56.01 \\
\hline Hangzhou & 686.79 & 16.3 & 29383.80 & 8439.76 & 2.58 & 0.70 & 5866.99 & 1946.53 & 565.11 & 114.78 \\
\hline Wuhan & 825.22 & 9.31 & 20736.14 & 6868.65 & 3.95 & 0.33 & 5600.43 & 2505.75 & 473.32 & 32.68 \\
\hline Guangzhou & 798.13 & 27.85 & 30168.80 & 8103.18 & 2.23 & 0.10 & 10454.12 & 3599.51 & 692.04 & 71.25 \\
\hline Shenzhen & 253.43 & 41.70 & 31956.64 & 7573.80 & 2.37 & 0.10 & 9811.32 & 3416.01 & 239.65 & 48.65 \\
\hline Chongqing & 3284.59 & 62.85 & 18023.60 & 5386.75 & 3.76 & 0.27 & 8069.28 & 3467.74 & 1559.58 & 95.20 \\
\hline Chengdu & 1144.40 & 35.90 & 20919.30 & 6630.27 & 2.87 & 0.16 & 5655.94 & 2486.02 & 736.90 & 69.03 \\
\hline
\end{tabular}

Notes: The data are annual and cover the period from 2005 to 2014 . The units of population, per capita disposable income, unemployment rate, regional GDP, and number of practitioners are in ten thousand, RMB, percentage, RMB hundred million, and ten thousand, respectively.

both have a population of more than 10 million (see Supplementary Appendix 2). This emphasizes that estimation bias will occur when estimating spatial econometric models by considering only the geographic SWM but not the economic SWM.

In this study, the main macroeconomic indicator variables contain the annual urban total population, number of practitioners, per capita disposable income of urban households, registered urban unemployment rate, fixed mortgage rate, and monthly returns of the Shanghai Composite Index (SCI, hereafter). We regard the loan rate with an over five-year maturity as proxy for the fixed mortgage rate because the fixed mortgage rate is generally in accordance with the bank benchmark loan rate with an over five-year maturity in China, and this long-term interest loan rate is set by the People's Bank of China (PBC). The selection of these control variables is mainly based on insights from well-established literature that evaluates the role of macroeconomic fundamentals in housing markets (Kallberg et al. 2014; Moscone et al. 2014; Zhang et al. 2014; Zhu et al. 2013). The data of these variables are from the following sources.

The monthly returns of the SCI and the annual urban total population data are obtained from the Chinese Stock Market and Accounting Research (CSMAR) financial database. The annual per capita disposable income of urban households and the annual registered urban unemployment rate data are taken from China City Statistics Yearbook. The annual fixed mortgage rate data are provided by the PBC. In constructing the economic SWM, we use variables including regional GDP, number of practitioners, per capita disposable income of urban households, and residential satisfaction of city dwellers. The reason for using the residential satisfaction of city dwellers is that we believe it is not only an important component of their quality of life but also determines the way they respond to their own residential environment. The annual regional GDP and the number of practitioners' data are obtained from the CSMAR database, while the data on the satisfaction level of the city dwellers are taken from the CIA. Table 3 presents the summary statistics for our variables ${ }^{9}$.

\subsection{Findings}

First, we test whether the multivariate GJRGARCH $(1,1)$ specification can successfully remove the autocorrelation in the residuals. We adopt the panel autocorrelation test to the squared standardized residuals of the following equation. The standardized residuals are calculated as quotients of the residuals and its conditional standard deviations. The $F$ statistics of the Wooldridge test of autocorrelation in the panel data for the one-period lagged squared standardized residuals in Eq. (15) is 4.818 . These results show that autocorrelation exists in the residuals in Eq. (15).

$$
\begin{aligned}
& Y_{n t}=\varphi Y_{n, t-1}+\rho\left[a W_{G}+(1-a) W_{E}\right] Y_{n t}+ \\
& \lambda\left[b W_{G}+(1-b) W_{E}\right] Y_{n, t-1}+X_{n t} \beta+u_{n}+v_{t}+e_{n t}, \\
& e_{n t}=\delta\left[c W_{G}+(1-c) W_{E}\right] e_{n t}+\varepsilon_{n t} .
\end{aligned}
$$

\footnotetext{
${ }^{9}$ For conciseness, Table 4 does not present the descriptive statistics of the fixed mortgage rates and the monthly returns of SCI. Because we only have annual data for the urban total population, the per capita disposable income of urban households, and the registered urban unemployment rates, we transform them into monthly data using quadratic-match sum/average conversion method through Eviews 8.
} 
Table 4 presents the regression results. In specifications 1 and 2, we allow for incorporating the geographic SWM and the economic SWM into the proposed model, respectively. The two specifications are our benchmark models. Specification 3 shows the results of the DSP-GARCH $(1,1)$ model proposed by Zhu et al. (2013) and specification 4 presents the results of Eq. (14). The results show that all the explanatory variables that are statistically significant have reasonable signs. Particularly, the contemporary growth rate of population, one-period lagged growth rate of per capita disposable income of urban households, and one-period lagged monthly returns of the SCI are significantly positively correlated with housing returns. Meanwhile, the oneperiod lagged growth rates of fixed mortgage rates are significantly negatively correlated with housing returns. However, only the macro-control policy issued by the State Council in May 2006 has a significantly positive impact on regional housing returns and volatilities. The findings imply that regional housing price variability is closely related to the national macroeconomic development indicators. For instance, the increase in per capita disposable income of urban households will increase the purchasing power of urban households and thus result in an increase in the demand for owner-occupied homes, which leads to an increase in housing prices.

Compared with the DSP-GARCH $(1,1)$ model of Zhu et al. (2013), the DSP-GJR-GARCH $(1,1)$ model is more suitable for capturing the price co-movement and volatility spillovers across China's regional housing markets. The results in specifications 1 and 2 indicate that both the geographic SWM and the economic SWM are essential in studying the price co-movement and volatility spillovers across regional housing markets. Notably, the coefficients $a, b$, and $c$ in specifications 4 and 5 have once more emphasized the importance of these two factors.

To eliminate any potential multicollinearity between the explanatory variables, we first consider a model specification that includes all the explanatory variables in both contemporaneous and oneperiod lagged forms. However, through correlation analysis, we find that the contemporaneous and one-period lagged growth rate of the population as well as the contemporaneous and one-period lagged growth rate of per-capita disposable income of urban households is highly correlated. Thus, we exclude some potential co-linear and insignificant variables and present the results in Table $4^{10}$.

\footnotetext{
$\overline{10}$ Details are in Supplementary Appendix 4. Given space limitations, we do not report the effects of other macrocontrol policies over the years on the housing returns and volatilities. These results are available upon request.
}

Results of both specifications 4 and 5 show that serial autocorrelations exist in housing returns because the coefficient for serial correlation is significantly different from zero. This finding implies that the housing returns for the previous period have a strong impact on the housing returns for the following period. Owing to low transaction frequencies and high transaction costs, investors often make real estate investment decisions on the basis of previous transaction information in housing markets. Furthermore, the coefficients of spatial dependence parameters $\rho, \delta$, and $\lambda$ are statistically significantly different from zero. The absolute values of parameters $\rho$ and $\delta$ are much larger than that of parameter $\lambda$. This fact suggests that the intensities of co-movements are stronger than the intensities of spatial dependencies. With respect to the contributions of the spatial weight matrices, the proportions of the geographic SWM in the compound SWMs for the contemporaneous, the one-period lagged spatial dependence in returns, and the spatial dependence in the error terms are $50.6 \%, 43.8 \%$, and $52.1 \%$, respectively. The results again emphasize that both the geographic SWM and the economic SWM are essential in studying the price co-movement and volatility spillovers across regional housing markets.

Table 5 presents the intensity matrix of price co-movement across 10 cities. As shown in Table 5, strong price co-movement appear not only among regions that are located close to each other such as Beijing-Tianjin, but also among regions that are located far apart but have similar economic development conditions like Wuhan-Tianjin. This finding indicates that both the geographic distance and the similarity of economic development have important effects on regional housing prices. However, the influence of the former seems to be much stronger than that of the latter.

In terms of the conditional variances, all the parameters of the multivariate GJR-GARCH $(1,1)$ model are statistically significant from zero. Compared with the values estimated from the stock markets data, the larger coefficient of the $\mathrm{ARCH}$ term $\left(\omega_{1}+\psi_{G}+\psi_{E}=0.334\right)$ indicates that investors react more quickly to innovations in housing markets than to those in stock markets. The relatively large coefficient of the GARCH term shows that volatility in housing markets persists for a long time. These results are in accordance with the findings of Zhu et al. (2013). The coefficient $\gamma=0.484$ shows that the leverage effects exist in China's regional housing markets. The existence of leverage effects suggests that investors react more 
Table 4. Regression results

\begin{tabular}{|c|c|c|c|c|c|c|c|c|c|c|}
\hline \multirow[t]{2}{*}{ Parameter } & \multicolumn{2}{|c|}{ Specification 1} & \multicolumn{2}{|c|}{ Specification 2} & \multicolumn{2}{|c|}{ Specification3 } & \multicolumn{2}{|c|}{ Specification 4} & \multicolumn{2}{|c|}{ Specification 5} \\
\hline & Estimate & S.E. & Estimate & S.E. & Estimate & S.E. & Estimate & S.E. & Estimate & S.E. \\
\hline$\beta_{p o p}$ & $0.122^{* * *}$ & 0.059 & $0.162^{*}$ & 0.086 & 0.060 & 0.105 & $0.165^{* *}$ & 0.074 & $0.206^{*}$ & 0.081 \\
\hline$\beta_{\text {income }, t-1}$ & $0.137^{* * * *}$ & 0.020 & $0.160^{* * *}$ & 0.030 & 0.029 & 0.036 & $0.145^{* * *}$ & 0.024 & $0.137^{* * *}$ & 0.024 \\
\hline$\beta_{\text {unemp }, t-1}$ & -0.007 & 0.024 & -0.031 & 0.036 & -0.029 & 0.040 & -0.011 & 0.029 & -0.053 & 0.028 \\
\hline$\beta_{\text {rate }, t-1}$ & $-0.018^{* *}$ & 0.007 & -0.016 & 0.010 & -0.013 & 0.013 & $-0.015^{*}$ & 0.009 & $-0.014^{*}$ & 0.008 \\
\hline$\beta_{S Z, t-1}$ & $0.004^{* *}$ & 0.002 & 0.004 & 0.003 & 0.003 & 0.004 & $0.004^{*}$ & 0.002 & $0.004^{*}$ & 0.002 \\
\hline$\beta_{\text {policy }}$ & $0.684^{* *}$ & 0.333 & 0.757 & 0.472 & $0.977^{* * *}$ & 0.319 & $0.740^{* * *}$ & 0.400 & -0.073 & 0.125 \\
\hline$\rho$ & $0.731^{* * *}$ & 0.022 & $0.700^{* * *}$ & 0.024 & $0.753^{* * *}$ & 0.038 & $0.726^{* * *}$ & 0.023 & $0.736^{* * *}$ & 0.019 \\
\hline$\delta$ & $-0.600^{* * *}$ & 0.042 & $-0.510^{* * *}$ & 0.053 & $-0.430^{* * *}$ & 0.124 & $-0.558^{* * *}$ & 0.070 & $-0.568^{* * * *}$ & 0.037 \\
\hline$\varphi$ & $0.276^{* * *}$ & 0.029 & $0.351^{* * *}$ & 0.028 & $0.397^{* * *}$ & 0.037 & $0.347^{* * *}$ & 0.039 & $0.384^{* * *}$ & 0.044 \\
\hline$\lambda$ & $-0.074^{* * *}$ & 0.015 & $-0.428^{* * *}$ & 0.044 & $-0.266^{* * *}$ & 0.048 & $-0.213^{* * *}$ & 0.043 & $-0.253^{* * * *}$ & 0.041 \\
\hline$\omega_{0}$ & $0.177^{* * * *}$ & 0.035 & $0.220^{* * *}$ & 0.043 & $0.406^{* * *}$ & 0.074 & $0.211^{* * *}$ & 0.036 & $0.122^{* * * *}$ & 0.030 \\
\hline$\omega_{1}$ & $0.083^{* * * *}$ & 0.032 & $0.082^{* * *}$ & 0.027 & $0.151^{* * *}$ & 0.033 & $0.076^{* * *}$ & 0.025 & $0.090^{* * *}$ & 0.028 \\
\hline$\omega_{2}$ & $0.201^{* * *}$ & 0.058 & $0.315^{* * *}$ & 0.051 & $0.238^{* * *}$ & 0.069 & $0.156^{* * *}$ & 0.056 & $0.231^{* * *}$ & 0.047 \\
\hline$\gamma$ & $0.489^{* * * *}$ & 0.067 & $0.428^{* * *}$ & 0.050 & - & - & $0.484^{* * *}$ & 0.068 & $0.449^{* * *}$ & 0.043 \\
\hline$\psi_{G}$ & $0.063^{* * *}$ & 0.015 & - & - & $0.073^{* * *}$ & 0.018 & $0.031^{* *}$ & 0.013 & 0.016 & 0.017 \\
\hline$\psi_{E}$ & - & - & $0.189^{* * *}$ & 0.050 & $0.401^{* * *}$ & 0.103 & $0.227^{* * *}$ & 0.054 & $0.465^{* * *}$ & 0.084 \\
\hline$a$ & - & - & - & - & $0.383^{*}$ & 0.210 & $0.506^{* * *}$ & 0.077 & $0.528^{* * *}$ & 0.065 \\
\hline$b$ & - & - & - & - & 0.635 & 0.504 & $0.438^{* * *}$ & 0.136 & $0.514^{* * *}$ & 0.130 \\
\hline$c$ & - & - & - & - & 0.421 & 0.343 & $0.521^{* * *}$ & 0.108 & $0.514^{* * *}$ & 0.067 \\
\hline$\xi$ & $4.714^{* * * *}$ & 1.167 & $5.717^{* * *}$ & 0.606 & - & - & $5.538^{* * *}$ & 0.000 & $0.281^{* *}$ & 0.136 \\
\hline$R^{2}$ & 0.508 & & 0.316 & & 0.377 & & 0.421 & & 0.426 & \\
\hline$L L$ & -1768.1 & & -1766.6 & & -1997.0 & & -1745.6 & & -1787.8 & \\
\hline$R M S E$ & 1.241 & & 1.463 & & 1.396 & & 1.345 & & 1.340 & \\
\hline
\end{tabular}

Notes: $\beta_{\text {pop }}, \beta_{\text {income,t-1}}, \beta_{\text {unemp t-1 }}$, and $\beta_{\text {rate }, t-1}$ represent coefficients of the contemporaneous growth rate of urban total population, one-period lagged growth rate of per capita disposable income of urban households, one-period lagged registered urban unemployment rate, and one-period lagged fixed mortgage rate, respectively. $\beta_{S Z, t-1}$ is the coefficient of the monthly returns of the SCI. $\beta_{\text {policy }}$ in specifications 4 and 5 are the coefficients for the dummy variable $D$, which is used to reflect the effects of the national macro-control policy issued by the State Council in May 2006 and by PBC in May 2014 on the regional housing returns, respectively. $R^{2}$ is the goodness-of-fit. $L L$ stands for the maximum log-likelihood function value. $R M S E$ represents the root-mean-square error. The signs $* * * * *$, and ${ }^{*}$ denote statistical significance at the $0.01,0.05$, and 0.1 levels, respectively. 
Table 5. Intensities of price co-movement across housing markets in 10 cities

\begin{tabular}{|c|c|c|c|c|c|c|c|c|c|c|}
\hline Region & Beijing & Tianjin & Shanghai & Nanjing & Hangzhou & Wuhan & Guangzhou & Shenzhen & Chongqing & Chengdu \\
\hline Beijing & & 0.3708 & & & & & & & & \\
\hline Tianjin & 0.3708 & & & & & 0.1727 & & & & 0.0298 \\
\hline Shanghai & & & & 0.3486 & 0.3613 & & & & & \\
\hline Nanjing & & & 0.3486 & & 0.3089 & & 0.1264 & & & \\
\hline Hangzhou & & & 0.3613 & 0.3089 & & & & & & \\
\hline Wuhan & & 0.1727 & & & & & & & & \\
\hline Guangzhou & & & & 0.1264 & & & & 0.3741 & & 0.0296 \\
\hline Shenzhen & & & & & & & 0.3741 & & & \\
\hline Chongqing & & & & & & & & & & 0.3474 \\
\hline Chengdu & & 0.0298 & & & & & 0.0296 & & 0.3474 & \\
\hline
\end{tabular}

Notes: Each element in the matrix is calculated as $\rho\left[a W_{G}+(1-a) W_{E}\right]$ and stands for the price co-movement between two cities from March 2005 to December 2014. If the intensity is not statistically significantly different from zero at 0.1 , we do not report it.

Table 6. Intensities of volatility spillovers across housing markets in 10 cities

\begin{tabular}{|c|c|c|c|c|c|c|c|c|c|c|}
\hline Region & Beijing & Tianjin & Shanghai & Nanjing & Hangzhou & Wuhan & Guangzhou & Shenzhen & Chongqing & Chengdu \\
\hline Beijing & & 0.0358 & & & & & & & & \\
\hline Tianjin & 0.0358 & & & & & 0.0885 & & & & 0.0188 \\
\hline Shanghai & & & & 0.0330 & 0.0333 & & & & & \\
\hline Nanjing & & & 0.0330 & & 0.0299 & & 0.0798 & & & \\
\hline Hangzhou & & & 0.0333 & 0.0299 & & & & & & \\
\hline Wuhan & & 0.0885 & & & & & & & & \\
\hline Guangzhou & & & & 0.0798 & & & & 0.0384 & & 0.0187 \\
\hline Shenzhen & & & & & & & 0.0384 & & & \\
\hline Chongqing & & & & & & & & & & 0.0565 \\
\hline Chengdu & & 0.0188 & & & & & 0.0187 & & 0.0565 & \\
\hline
\end{tabular}

Notes: Each element in the matrix is calculated as $\psi_{G} W_{G}+\psi_{E} W_{E}$ and stands for the volatility spillover between two cities from March 2005 to December 2014. If neither geographic nor economic-based intensity is not statistically significantly different from zero at 0.1 , we do not report it.

strongly to bad news than to good news in housing markets.

In addition, we have tested whether the autocorrelation in the residuals has been removed by using our multivariate GJR-GARCH $(1,1)$ specification. The $F$ statistics of the Wooldridge test for autocorrelation in panel data for the one-period lagged squared standardized residuals in Eq. (14) is 0.691 . These results indicate that the autocorrelation in the residuals have been successfully removed using our proposed model.

The significantly positive coefficients $\psi_{G}$ and $\psi_{E}$ show that the volatility spillover effects exist among regions that are closely located to each other or regions that have similar economic development conditions. However, the influences of the latter seem to be much stronger than the former. Table 6 presents the intensity matrix of the volatility spillovers across 10 cities. These results are highly similar to those presented in Table 5, namely, strong volatility spillovers appear not only among regions that are closely located to each other but also among regions that are located far apart but have similar economic development conditions.

Figure 2 presents the time-series plots of the urban composite indices of the 10 large cities and their conditional variances estimated by our proposed model. As shown in Figure 2, each city composite index is slowly increasing. This result indicates that the housing price of each city has been on an uptrend since 2005. With regard to the conditional variances, Figure 2 clearly shows that sharp increases in volatility occurred in the period approximately from April to July 2006. The most obvious volatility occurred in Nanjing whose conditional variance rose to $59.04 \%$ in March 2006. Furthermore, we are interested in the reasons that drove such high volatility in this period. Through close investigation, we found that the General Office of the State Council in China enacted the "Six policies on housing market intervention in China" on May 24, 2006. This policy aimed to adjust the housing demand structure, rectify and standard- 
252

Y. Went, P. Gong

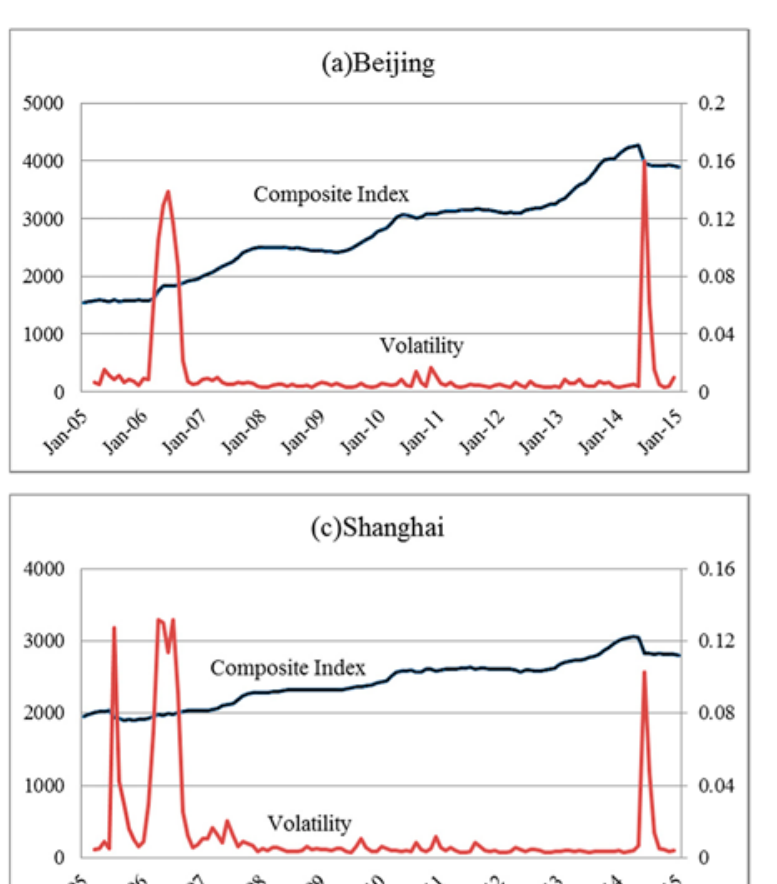

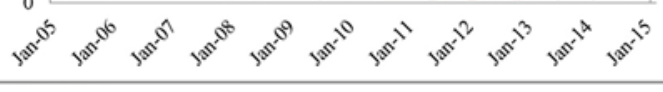
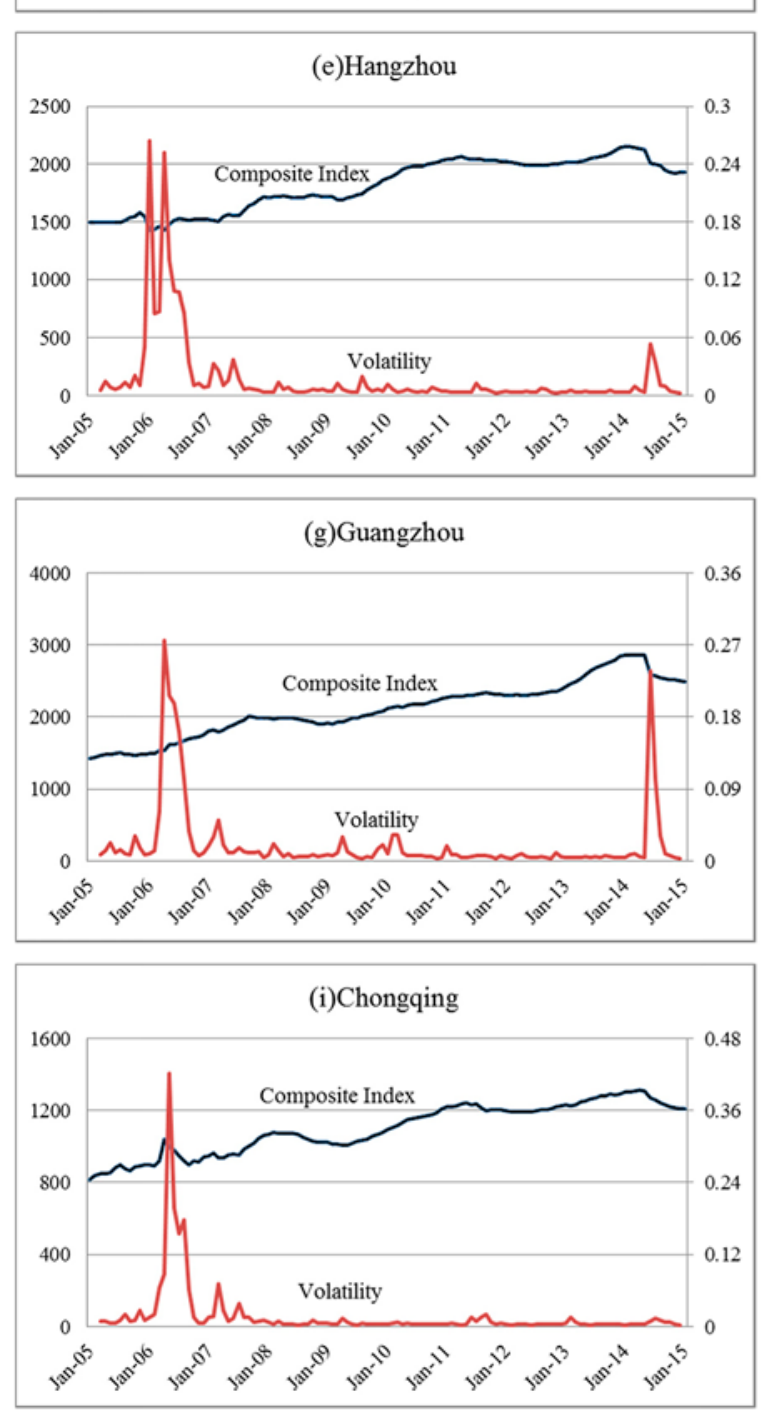
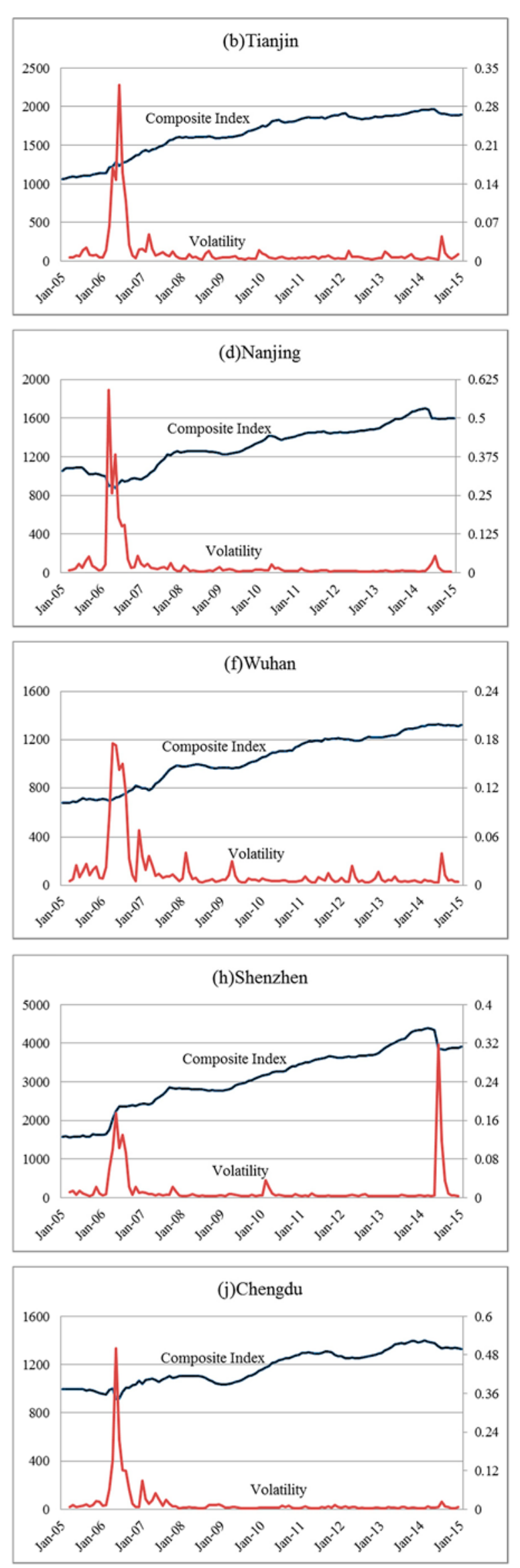

Fig. 2. Housing prices and volatilities of 10 large cities in China 
ize the real estate market order, and promote the healthy development of China's housing markets. After the policy was announced, both banks and investment institutions actively invested in real estate, which led to an increase in housing prices. Another sharp increase in volatility occurred approximately from April to July 2014. However, only Beijing, Shanghai, Guangzhou, and Shenzhen exhibited obvious fluctuation in housing prices at the time. These results may imply the beginning of China's regional housing market differentiation. One reason may be the implementation of the five directives issued by PBC on May 12, 2014 to stabilize regional housing prices.

\section{CONCLUSIONS}

This study empirically investigated whether volatility spillover effects exist and what drove the comovements in housing returns across 10 regional housing markets in China from 2005 to 2014. The main findings are presented as follows:

First, the results show that the contemporaneous growth rates of population, the one-period lagged growth rates of the per capita disposable income of urban households, and the one-period lagged returns of the SCI are significantly positively correlated with housing returns, which is in accordance with the findings of Zhu et al. (2013). Meanwhile, the one-period lagged growth rates of fixed mortgage rates are significantly negatively correlated with housing returns. These results imply that regional housing price variability is closely related to the national macroeconomic development indicators.

Second, the results indicate that the housing returns of regions in China that are in close geographic proximities and economic similarities exhibit strong co-movement and volatility spillovers. However, strong forms of the price co-movement occur among regions which are located close to one another. Evidence of the significantly positive leverage effects in China's regional housing markets suggests that investors react more strongly to bad news than to good news in housing markets.

Third, the regional housing markets can mutually affect each other through housing returns, unexpected shocks, and conditional variances. Therefore, investors should be aware of the interactions among regional housing markets. Considering only the geographic adjacencies regardless of the similarities in economic development conditions may lead to ineffectiveness of the portfolio strategy and underpricing of real-estate-related assets.
Finally, by employing a dummy variable method, we examined whether the key macro-control policies on the housing markets issued by the State Council over the years have significant effects on the regional housing returns and fluctuations. We found that only the macro-control policy issued by the State Council in May 2006 had a significant and positive effect on regional housing returns and volatilities. This result is a useful signal for policy makers and can explain why China's macro-control policies aimed at promoting the steady and sound development of the housing market since 2005 have had a minimal impact on housing prices throughout the country. Since the price co-movement among regional housing markets is clear, the authorities must realize this point and take relevant and effective measures to fight housing price appreciation.

A useful extension of this study is to incorporate the time-varying SWM into the proposed DSP-GJR-GARCH $(1,1)$ model. The reasons are as follows. First, Lee and Yu (2012) found that when spatial weight matrices substantially vary over time, a model misspecification of a time-invariant spatial weight matrix may cause substantial bias in the model estimation. Second, Seya et al. (2013) and Cheng et al. (2014) emphasized the importance of selecting of dynamic spatial weight matrices for DSP data models and discussed certain rules for various specification approaches of time-varying spatial weight matrices.

\section{ACKNOWLEDGMENTS}

The authors are grateful to the Editor Prof. Eddie Chi-man Hui and the two anonymous referees for their helpful comments and suggestions. This work is supported by the National Natural Science Foundation of China (Key Project No. 71231005) and Research Fund for the Doctoral Program of Higher Education of China (No. 20110142110068). Any remaining errors are solely ours.

\section{REFERENCES}

Alkan, L. 2015. Housing market differentiation: the cases of Yenimahalle and Çankaya in Ankara, International Journal of Strategic Property Management 19(1): 13-26. https://doi.org/10.3846/164871 5X.2014.1000429

Anselin, L. 1988. Spatial econometrics: methods and models. Dordrecht: Kluwer Academic Publishers. https://doi.org/10.1007/978-94-015-7799-1

Apergis, N.; Simo-Kengne, B. D.; Gupta, R.; Chang, T. 2015. The dynamic relationship between house pric- 
es and output: evidence from US metropolitan areas, International Journal of Strategic Property Management 19(4): 336-345. https://doi.org/10.3846/164871 5X.2015.1072857

Baltagi, B. H.; Fingleton, B.; Pirotte, A. 2014. Estimating and forecasting with a dynamic spatial panel data model, Oxford Bulletin of Economics and Statistics 76(1): 112-138. https://doi.org/10.1111/obes.12011

Bauwens, L.; Laurent, S.; Rombouts, J. V. K. 2006. Multivariate GARCH models: a survey, Journal of Applied Econometrics 21(1): 79-109. https://doi.org/10.1002/jae.842

Bollerslev, T. 1986. Generalized autoregressive conditional heteroskedasticity, Journal of Econometrics 31(3): 307-327. https://doi.org/10.1016/03044076(86)90063-1

Bollerslev, T. 1990. Modelling the coherence in short-run nominal exchange rates: a multivariate generalized ARCH model, Review of Economics and Statistics 72(3): 498-505. https://doi.org/10.2307/2109358

Bollerslev, T.; Engle, R. F.; Wooldridge, J. M. 1988. A capital asset pricing model with time-varying covariances, Journal of Political Economy 96(1): 116-131. https://doi.org/10.1086/261527

Brady, R. R. 2014. The spatial diffusion of regional housing prices across U.S. states, Regional Science and Urban Economics 46: 150-166. https://doi.org/10.1016/j.regsciurbeco.2014.04.003

Brunauer, W.; Lang, S.; Umlauf, N. 2013. Modelling house prices using multilevel structured additive regression, Statistical Modelling 13(2): 95-123. https:// doi.org/10.1177/1471082X13475385

Case, A. C.; Rosen, H. S.; Hines Jr, J. R. 1993. Budget spillovers and fiscal policy interdependence: evidence from the states, Journal of Public Economics 52(3): 285-307. https://doi.org/10.1016/00472727(93)90036-S

Cheng, T.; Wang, J.; Haworth, J.; Heydecker, B.; Chow, A. 2014. A dynamic spatial weight matrix and localized space-time autoregressive integrated moving average for network modeling, Geographical Analysis 46(1): 75-97. https://doi.org/10.1111/gean.12026

Chiang, S.-h. 2014. Housing markets in China and policy implications: comovement or ripple effect, China \& World Economy 22(6): 103-120. https://doi.org/10.1111/cwe.12094

Chiang, S.-h. 2016. Interaction among real estate properties in China using three submarket panels, Habitat International 53: 243-253. https://doi.org/10.1016/j. habitatint.2015.11.038

Dolde, W.; Tirtiroglu, D. 2002. Housing price volatility changes and their effects, Real Estate Economics 30(1): 41-66. https://doi.org/10.1111/15406229.00029

Elhorst, J. P. 2005. Unconditional maximum likelihood estimation of linear and log-linear dynamic models for spatial panels, Geographical Analysis 37(1): 85-106. https://doi.org/10.1111/j.1538-4632.2005.00577.x

Elhorst, J. P. 2014. Spatial econometrics: from cross-sectional data to spatial panels. New York: Springer. https://doi.org/10.1007/978-3-642-40340-8
Engle, R. 2002. Dynamic conditional correlation, Journal of Business \& Economic Statistics 20(3): 339-350. https://doi.org/10.1198/073500102288618487

Engle, R. F. 1982. Autoregressive conditional heteroscedasticity with estimates of the variance of United Kingdom inflation, Econometrica 50(4): 987-1007. https://doi.org/10.2307/1912773

Engle, R. F.; Ghysels, E.; Sohn, B. 2012. Stock market volatility and macroeconomic fundamentals, Review of Economics and Statistics 95(3): 776-797. https://doi.org/10.1162/REST_a_00300

Engle, R. F.; Kroner, K. F. 1995. Multivariate simultaneous generalized ARCH, Econometric Theory 11(1): 122-150. https://doi.org/10.1017/S0266466600009063

Glosten, L. R.; Jagannathan, R.; Runkle, D. E. 1993. On the relation between the expected value and the volatility of the nominal excess return on stocks, Journal of Finance 48(5): 1779-1801. https://doi. org/10.1111/j.1540-6261.1993.tb05128.x

Gong, P.; Weng, Y. 2016. Value-at-Risk forecasts by a spatiotemporal model in Chinese stock market, Physica A: Statistical Mechanics and its Applications 441: 173-191. https://doi.org/10.1016/j.physa.2015.08.052

Hsiao, C.; Hashem Pesaran, M.; Kamil Tahmiscioglu, A. 2002. Maximum likelihood estimation of fixed effects dynamic panel data models covering short time periods, Journal of Econometrics 109(1): 107-150. https://doi.org/10.1016/S0304-4076(01)00143-9

Hui, E. C. M.; Yue, S. 2006. Housing price bubbles in Hong Kong, Beijing and Shanghai: a comparative study, Journal of Real Estate Finance and Economics 33(4): 299-327. https://doi.org/10.1007/s11146006-0335-2

Hui, E. C.; Chan, K. K. K. 2013. Contagion across real estate and equity markets during European sovereign debt crisis, International Journal of Strategic Property Management 17(3): 305-316. https://doi.org/10.3846/1648715X.2013.822837

Kallberg, J. G.; Liu, C. H.; Pasquariello, P. 2014. On the price comovement of U.S. residential real estate markets, Real Estate Economics 42(1): 71-108. https://doi.org/10.1111/1540-6229.12022

Kelejian, H. H.; Piras, G. 2014. Estimation of spatial models with endogenous weighting matrices, and an application to a demand model for cigarettes, $R e$ gional Science and Urban Economics 46: 140-149. https://doi.org/10.1016/j.regsciurbeco.2014.03.001

Lee, L.-f.; Yu, J. 2012. QML estimation of spatial dynamic panel data models with time varying spatial weights matrices, Spatial Economic Analysis 7(1): 31-74. https://doi.org/10.1080/17421772.2011.647057

Ma, L.; Liu, C. 2013. Spatio-temporal analysis of house price convergence based on a demographical distance, International Journal of Strategic Property Management 17(3): 263-277. https://doi.org/10.3846 /1648715X.2013.822031

Miao, H.; Ramchander, S.; Simpson, M. W. 2011. Return and volatility transmission in U.S. housing markets, Real Estate Economics 39(4): 701-741. https://doi.org/10.1111/j.1540-6229.2010.00303.x 
Michayluk, D.; Wilson, P. J.; Zurbruegg, R. 2006. Asymmetric volatility, correlation and returns dynamics between the U.S. and U.K. securitized real estate markets, Real Estate Economics 34(1): 109-131. https://doi.org/10.1111/j.1540-6229.2006.00161.x

Moscone, F.; Tosetti, E.; Canepa, A. 2014. Real estate market and financial stability in US metropolitan areas: a dynamic model with spatial effects, Regional Science and Urban Economics 49: 129-146. https://doi.org/10.1016/j.regsciurbeco.2014.08.003

Parent, O.; LeSage, J. P. 2011. A space-time filter for panel data models containing random effects, Computational Statistics \& Data Analysis 55(1): 475-490. https://doi.org/10.1016/j.csda.2010.05.016

Seya, H.; Yamagata, Y.; Tsutsumi, M. 2013. Automatic selection of a spatial weight matrix in spatial econometrics: application to a spatial hedonic approach, Regional Science and Urban Economics 43(3): 429-444. https://doi.org/10.1016/j.regsciurbeco.2013.02.002

Shih, Y.-N.; Li, H.-C.; Qin, B. 2014. Housing price bubbles and inter-provincial spillover: evidence from China, Habitat International 43: 142-151. https://doi.org/10.1016/j.habitatint.2014.02.008
Shiller, R. J. 1994. Macro markets: creating institutions for managing society's largest economic risks. Oxford: Oxford University Press.

Wang, M.; Wong, M. C. S.; Granato, J. 2015. International comovement of economic fluctuations: a spatial analysis, World Development 67: 186-201.

https://doi.org/10.1016/j.worlddev.2014.10.016

Weng, Y.; Gong, P. 2016. Modeling spatial and temporal dependencies among global stock markets, Expert Systems with Applications 43: 175-185. https://doi.org/10.1016/j.eswa.2015.09.002

Wheeler, D. C. 2014. Geographically weighted regression, in Handbook of Regional Science. Heidelberg: Springer, 1435-1459. https://doi.org/10.1007/978-3642-23430-9_77

Zhang, T.; Gerlowski, D.; Ford, D. 2014. Housing price variability: national and local impacts, Applied Economics 46(28): 3494-3502. https://doi.org/10.1080/00 036846.2014 .929628

Zhu, B.; Füss, R.; Rottke, N. B. 2013. Spatial linkages in returns and volatilities among U.S. regional housing markets, Real Estate Economics 41(1): 29-64. https://doi.org/10.1111/j.1540-6229.2012.00337.x 